\title{
Development of Current Financial Derivative Markets
}

\author{
Adigamova F.F.a \\ Galimardanova Yu.M.b \\ ${ }^{a b}$ Kazan Federal University, Institute of Management, Economics and Finance, Kazan, 420008, Russia
}

\section{Doi:10.5901/mjss.2015.v6n1s3p507}

\begin{abstract}
This paper covers the pressing challenges of derivatives market. Particularly, the authors substantiate the need for definitions to be clarified for futures instruments used in Russia. In addition, Russian derivative market is exposed to a number of factors, which analysis is required to ascertain its strengths and weaknesses and to determine the prospects for its further development.
\end{abstract}

Keywords: financial derivatives; futures; securities market; securities indexes; correlation-regression analysis; factor analysis.

\section{Introduction}

By now, the derivatives market takes a major lead in the global financial system. The futures contracts determine the prices for primary commodities. The derivatives have a significant effect on the share indexes, which, in turn, allow for investment in the portfolio of more liquid shares of a particular country using the only asset. The development of Russian derivatives market was a challenge. Failure of the short-term bond system in 1998 resulted in complete shutdown of the futures market. Significant activity started after a few years only.

The market has experienced explosive growth and shrinkage in recent years, specifically, at the acute phase of the global financial market. However, the flagship derivatives exchange of the country - the Russian Trading System Stock Exchange Futures Section - is within the top tens of largest world exchanges with the number of futures and options contracts concluded. The Russian derivatives market became an important part of the financial system so that the results of its functioning influence the entire financial sector. Orlova M. and Khafizova A. examines the role of the tax component of innovative activity assessment in the Russian Federation [1].

\section{Theory}

Russian experts draw the serious fire of mixing the definition "futures" and "derivatives". The supporters of "financial derivative" be introduced into the civil laws define this definition as a special type of property (a right in things asset) or as an individual contract type. Currently, there several definitions of derivatives market instruments equally used in Russian theory and practice: "derivative", "financial derivative" and "futures". The variety of definitions used prevents the Russian financial market from further growth. Using different definitions leads to many inconsistencies in practical activity of the traders, particularly, for the accounting and taxation of deals with these instruments.

The definition "derivative" is frequently used in Russian business environment. Besides, the German law, which is the closet one to the Russian law, also uses the definition "derivate". We have proposed the following definition for derivative: it is a forward financial instrument, which binds or entitles the contract parties to undertake as provided by the contract in terms of derivation of the contract value from the performance of an underlying asset and its final settlements. Therefore, this definition of the derivative rectifies most of the downsides and defects of existing theoretical researches and Russian laws. In addition, an exhaustive list of underlying assets means significant degradation of the market and its growth.

\section{Results}

Considering the individual segments of Russian derivatives market in details, the first thing the securities derivatives say futures and options should focus on is share indexes and single shares. Currently, the trading in this sector of the 
derivatives market concentrates at the Moscow Central Stock Exchange of the Russian Trading System. The futures vs. options turnover seeks toward futures significantly. The monthly percentage of the options is $3 \%$ of the total forward contract trading, where the securities indexes are the underlying assets, while the options on equity futures have increased every month to average at about $8 \%$. The options take less than $2 \%$ of the total standardized contract trading every month, where the rates of interest, commodities and foreign currencies are the underlying assets. Snider, L. examines the deals with different types of securities on the stock market [2].

The derivatives market participants are another significant factor of the derivatives market. There are three types of trading participants: Speculators, arbitrageurs and hedgers. Nazarova, V. provides a sufficiently detailed study of how the financial options hedging is imperfect on the Russian derivatives market [3]. The studies of Salmina S.V., Galimardanova Yu.M. and Khafizova A. R. describe in details tax debt individual customers in the Russian Federation [4].

Generally, the speculators handle the most liquid instruments, RTS index futures and equity futures. The commercial banks and export/import-oriented companies that hedge the foreign exchange risks are the hedgers. The management companies that mitigate the portfolio risks through the forward contracts are also among the hedgers. The current hedging instrument issues are examined by Ahmad A.A., Ab. Halim M.A.A. and Nordin, N. [5].

Only professions can trade at the stock exchanges. 135 trading participants operate at the FORTS trading floor, the Saint-Petersburg Exchange provides floor for 21 participants and the MICEX Derivatives Market hosts 163 participants. A detailed study of issues associated with corporate management of financial instruments is provided in the papers of the following authors: Chen C.-L., Fan H.-S. and Yang Y.-M. [6].

The price for RTS future, which determines the growth of the Russian derivatives market, is linked to various factors both the external and the internal, and is required to fix the relationship between the RTS future price level and the factors influencing it. In our hypothesis that the derivatives market is exposed to different factors, we determine the following factors having a rather strong effect on the RTS future price: Price per 1 US Dollar; price per 1 barrel of Light crude oil; contract trading volume at the FORTS main market; the Hang Seng Index; and the BSE Sensex Index. The behaviour of crude oil prices is a determinant, which characterises the dynamics of the domestic equity market and influences the global markets. A detailed study of derivatives pricing is provided in the papers of the following authors: Lyuu Y.-D., Wen K.-W. and Wu Y.-C. [7].

The relation between the Russian stock indexes, the Russian stock market and oil prices is obvious. This dependence became more evident after the financial crises. Once the RTS index has dropped to 500 points, the Russian stocks also moved following the oil prices either being behind or ahead at particular instances. The studies of De Falco M. and Di Stasi D. describe in details how the derivatives are used for risk management [8].

The price per 1 US Dollar is one of the factors that influence the RTS future price as the RTS index is calculated in dollars. Moreover, the Asian indexes have a quite strong effect on the Russian derivatives market. Malkawi B.H. describes how the derivatives are applied by western standards of jurisprudence and Islamic financial system based on the comparative approach [9]. It is not improbable that the Russian stock market would adapt to the extension of influence by China and India as well. Therefore, our hypothesis also includes the influence of both Chinees and Indian indexes on the Russian derivatives market.

We believe that the FORTS trading volume has an effect on the RTS future price as well, but any way the liquid instruments are not too many. The problems of derivatives liquidity and historical deregulation aspects are covered by Funk, R.J. and Hirschman, D. [10]. We took monthly data to find the correlation with the variables and to construct a regression model. The Correlation software outputs a matrix of pair correlation coefficients as shown in Table 1.

Table 1. Matrix of pair correlation coefficients

\begin{tabular}{|c|c|c|c|c|c|c|}
\hline & 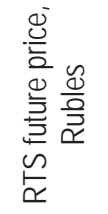 & 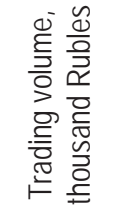 & 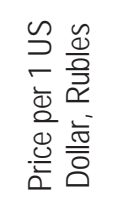 & 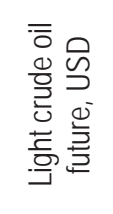 & 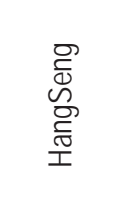 & 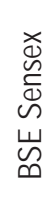 \\
\hline RTS future price, Rubles & 1 & & & & & \\
\hline Trading volume, thousand Rubles & -0.5646 & 1 & & & & \\
\hline Price per 1 US Dollar, Rubles & -0.9696 & 0.3865 & 1 & & & \\
\hline Light crude oil future, USD & 0.5933 & -0.2737 & -0.5623 & 1 & & \\
\hline HangSeng & 0.9522 & -0.6396 & -0.9265 & 0.5368 & 1 & \\
\hline BSE Sensex & 0.8641 & -0.6484 & -0.8220 & 0.5295 & 0.8800 & 1 \\
\hline
\end{tabular}


Based on Table 1 data analysis, the following conclusions can be made: Linearly, the resulting variable $Y$ strongly depends on the factor variable $X 2$ : $r(Y ; X 2)=-0.9696$. A rather strong statistical link is also observed between the linear variable $Y$ and the factors of HangSeng Index and BSE Sensex Index.

A mutual dependence of the factors will be found by the regression analysis having the link be presented in a strict analytical form. The results of the regression statistics analysis and calculations are given in Table 2.

Table 2. Regression analysis

\begin{tabular}{|l|c|c|c|c|}
\hline & Coefficients & Standard error & t-tests & P-value \\
\hline Variable Y & 7020.7574 & 1518.873381 & 4.6223 & 0.00360648 \\
\hline Trading volume, thousand Rubles & $6,93 \mathrm{E}-08$ & $2.27064 \mathrm{E}-08$ & -3.0532 & 0.02242001 \\
\hline Price per 1 US Dollar, Rubles & -154.7792 & 29.15641975 & -5.3086 & 0.00181486 \\
\hline Light crude oil future, USD & 1.5227 & 1.648656607 & 0.9236 & 0.39130982 \\
\hline HangSeng & -0.0181 & 0.022760205 & -0.7962 & 0.45625917 \\
\hline BSE Sensex & -0.0077 & 0.022047116 & -0.3505 & 0.73792817 \\
\hline
\end{tabular}

The R squared also being a coefficient of determination is a number that indicates how well data fit a statistical model sometimes simply a line or curve. It is 0.986 in our calculations, which means variability of the model parameters. The multiple $R$ coefficient of the multiple $R$ correlation expresses a degree of dependence between independent variables $(X)$ and a dependent variable $(Y)$. The calculations resulted in the multiple $R$ coefficient be 0.9932 , i.e. the link between the variables is very strong. The normalised $R$ squared is an $R$ squared corrected to a number of degrees of freedom (df) being 11. The regression equation will then yield:

$Y=6.93 E-08 * X 1-154.77 * X 2+1.5227 * X 3-0.0181 * X 4-0.0077 X 5+7020.75$ (1.)

Directions of the link between the variables based on the signs (negative or positive) of the regression coefficients (coefficient b) will be determined from this equation. In our case, the regression coefficient will have a positive sign; therefore, the relationship is also positive (direct).

The resulting equation is assumed to be statistically assessed using an F-test, which targets the ability of factors in question to explain a significant part of oscillation of function $Y$. The importance of the coefficient of determination should be verified using the F-ratio test.

The F-test will be determined by formula:

$F=\frac{R^{2}}{1-R^{2}} \cdot \frac{N-m}{m-1},(2)$

where $m=5$ - the number of parameters in the regression equation;

$\mathrm{N}=12$ - the number of observations in the sampling population.

The F-distribution with the degrees of freedom $v 1=m-1=5-1=4$ and $v 2=N-m=12-5=7$ is the mathematical model of F-ratio test statistical distribution. The F-test critical value at $\alpha=0.05$ and with the degrees of freedom $v 1=4$ and $v 2=7$ is $F_{\text {critical }}(0.005 ; 4 ; 7)=4.12$. $F_{\text {calculated }}$ was 319.98 . Therefore, $F_{\text {calculated }}$ is greater than $F_{\text {critical }}$ suggesting that the regression equation is statistically important and the coefficient of determination is other than zero.

We have verified the regression equation for importance. The effect of particular factors from $X_{1}$ through $X_{5}$ on the variable $Y$ should be further determined. Hence, the regression of coefficients from $b_{1}$ through $b_{5}$ needs be determined.

To assess the quality of the model using the Student's test, the actual value of this test (tobservation) is compared with the critical value tcritical taken from the Student's test table including the given importance $(\alpha=0.05)$ the number of the degrees of freedom $(n-2)$. If tobservation $>$ tcritical, then the pair correlation coefficient is acknowledged as a significant coefficient. The calculated tests are provided in Table 4. The F-test critical value at $\alpha=0.05$ and $v=9$ is tcritical $(0.005 ; 9)=$ 2.26 .

Table 4. Student's t-test

\begin{tabular}{|c|c|c|c|}
\hline Factor & tobservation & $t_{\text {critical }}$ & Importance \\
\hline $\mathrm{x} 1$ & 2.05 & 2.26 & Insignificant \\
\hline $\mathrm{x} 2$ & 11.8 & 2.26 & Significant \\
\hline $\mathrm{x} 3$ & 2.31 & 2.26 & Significant \\
\hline $\mathrm{x} 4$ & 9.35 & 2.26 & Significant \\
\hline $\mathrm{x} 5$ & 5.15 & 2.26 & Significant \\
\hline
\end{tabular}


The factors selected for building a regression equation and model are significant, i.e. the regression coefficient is statistically significant and differs from zero. The verification for significance gives quite consistent results suggesting that all factors, which we have picked, are statistically significant. The statistical analysis of the regression equation allows for interpretation of the regression coefficients.

The absolute term (drift) b0 equal to 7020.75 should be understood as follows: The RTS future price is 7020.75 , when all effective factors are absent. However, it is assumed that the indicated population misses similar cases (the factors are present constantly). Therefore, the drift b0 should be discussed as an ancillary quantity required for optimal predictions and should not be interpreted so literally. The regression coefficients from b1 through b5 should be considered as a level of effect of each several variables on the RTS future price, if all other independent variables remain constant. It should be noted that the studies that support our conclusions are described by Yelnikova, Y. [11].

Thus, the coefficient b1 equal to $6.93 \mathrm{E}-08$ means that the growth of trading volumes at the RTS futures and options market by 1 per cent will increase the RTS future price by $6.93 \mathrm{E}^{-08} \%$, all other thing being equal. The low coefficient can be explained by that all measures in the final regression equation are determined in Rubles, Dollars and percentage points while this factor is merely in thousand Rubles that is to say the factors vary in scales. The coefficients $b_{2}$ through $b_{5}$ have the same effect on the RTS future price and may be used for its prediction. All the mentioned regression coefficients show the effect on the parameter of only one variable provided always that all other variables (factors) are unaltered. Vasudev, H.M. also examines credit derivatives and the dodd-frank act.

\section{Conclusions}

Summarising the results of the correlation-regression analysis, it may be concluded that this or a similar model is applicable for further studies. Varying the amount and set of factors, and analysing different periods, we may achieve a more accurate result even though we can consider the existing result acceptable. The results of the regression analysis suggest our confirmation the price per 1 US Dollar and per a barrel of Light crude oil having a strong effect on the Russian derivatives market. This effect was one of the most significant factors, once again providing support for a strong dependence of the Russian stock and derivatives markets particularly on foreign factors. A great effect, which Chinese and Indian Indexes have on the global and Russian markets, is the result of great importance in our analysis. A few years ago, it was hard to imagine that undeveloped Chinese and Indian stock markets would play an important role globally. Now it is a reality to regard. The only factor, which is so influencing the RTS future price, is the trading volume. This is clear since the current level of liquidity of our market is not so high and plenty stable enough.

\section{References}

Orlova M., Khafizova A. The tax component of innovative activity assessment in the Russian Federation // Life Science Journal $2014 ; 11$ (11). - pp.328-333.

Snider, L. Interrogating the Algorithm: Debt, Derivatives and the Social Reconstruction of Stock Market Trading // Critical Sociology Vol. 40, Issue 5, 1 September 2014, Pages 747-761.

Nazarova, V., Evaluation of the effectiveness of methods of the imperfect hedging of financial options on the Russian forward market // Journal of Derivatives and Hedge Funds Vol. 20, Issue 1, February 2014, Pages 28-51.

Salmina S.V., Galimardanova Yu.M., Khafizova A. R. Tax Debt Individual Customers in the Russian Federation // Mediterranean Journal of Social Sciences Vol.5, No.24, November 2014. - pp.412-417.

Ahmad, A.A., Ab. Halim, M.A.A., Nordin, N. The viability hedging instruments in current application // International Business Management Vol. 8, Issue 6, 2014, Pages 327-335.

Chen, C.-L., Fan, H.-S., Yang, Y.-M. The effects of corporate governance and accounting rule changes on derivatives usage // Review of Derivatives Research Vol. 17, Issue 3, 2 October 2014, Pages 323-353.

Lyuu, Y.-D., Wen, K.-W., Wu, Y.-C. Performance of GPU for pricing financial derivatives: Convertible bonds // Journal of Information Science and Engineering, Vol. 30, Issue 1, January 2014, Pages 141-155.

De Falco, M., Di Stasi, D. Financial derivatives for risk management in shipping operations: A simulation model applied to the oil and gas sector // 2014 International Conference on Advanced Logistics and Transport, ICALT 2014, 2014, Article number 6866335, Pages 336-343, 2014 International Conference on Advanced Logistics and Transport, ICALT 2014; Hammamet; Tunisia; 1 May 2014 through 3 May 2014; Category numberCFP14VLT-ART; Code 107274.

Malkawi, B.H. Financial derivatives between western legal tradition and islamic finance: A comparative approach // Journal of Banking Regulation, Vol. 15, Issue 1, January 2014, Pages 41-55.

Funk, R.J., Hirschman, D. Derivatives and Deregulation: Financial Innovation and the Demise of Glass-Steagall // Administrative Science Quarterly, Vol. 59, Issue 4, 8 December 2014, Pages 669-704.

Yelnikova, Y. Evaluation of the efficiency of state regulation on the derivatives market // Investment Management and Financial 
Innovations Vol. 11, Issue 4, 2014, Pages 85-91.

Vasudev, H.M., Credit derivatives and the dodd-frank act: Is the regulatory response appropriate // Journal of Banking Regulation Vol. 15, Issue 1, January 2014, Pages 56-74. 